\title{
Estudo do Perfil dos Alunos do Curso de Matemática Aplicada - Bacharelado: entendendo as razões para o baixo rendimento dos acadêmicos
}

\author{
Analyzing Applied Mathematics graduation students' profile: discussing the reasons \\ of the low academic results during the first semester at the University.
}

\author{
Bárbara Denicol do Amaral Rodriguez ${ }^{* 1}$, Cinthya Maria Schneider Meneghetti ${ }^{2}$ e \\ Cristiana Andrade Poffal ${ }^{3}$ \\ 1,2,3 Universidade Federal do Rio Grande (FURG), RS, Brasil
}

\begin{abstract}
Resumo
Este artigo pretende exibir e justificar uma relação entre a quantidade de ingressantes e de egressos de um curso de Matemática Aplicada. Através de um estudo qualitativo dos dados produzidos, pretende-se discutir parte dos problemas de aprendizagem das disciplinas do primeiro semestre do curso, tais como a falta de domínio dos conteúdos matemáticos trabalhados nos ensinos fundamental e médio. Neste caso, os alunos não estão preparados e não avançam nas disciplinas da graduação, pois apresentam lacunas na sua formação quanto aos fundamentos necessários para a aprendizagem da matemática do ensino superior. Através de um questionário, foram coletados dados referentes à formação escolar básica, conhecimentos matemáticos prévios e principais dúvidas dos alunos. Os resultados permitem traçar um perfil do aluno e sugerem a necessidade de agregar maneiras alternativas de complementar sua formação básica.
\end{abstract}

Palavras-chave: Matemática Aplicada, ensino superior, baixo rendimento, disciplinas básicas.

\begin{abstract}
This paper aims to show and justify a relation between the number of new students and egress of Applied Mathematics course. Analyzing qualitative data, we intend to discuss learning problems related to the subjects of the course's first semester, such as the lack of mastery of the mathematics studied during elementary and high school. In this case, students are not prepared and do not approve the graduation subjects, as they have significant gaps in their academic fundamental training which is required to learning. By means of a survey, we collect data referring to elementary school, prior knowledge and students' main doubts. The results allow defining a student profile and suggest the need of adding alternative ways to complement their basic education.
\end{abstract}

Keywords: Applied Mathematics, higher education, low academic results, basic subjects. 


\section{Introdução}

$\mathrm{O}$ curso de Matemática Aplicada Bacharelado da Universidade Federal do Rio Grande (FURG) foi criado a partir da Deliberação no 012/2008 do Conselho de Ensino, Pesquisa e Extensão da FURG de 16 de maio de 2008. Ao longo dos primeiros cinco anos e meio de existência do curso, tornou-se evidente o aumento dos percentuais de evasão e reprovação. Neste perído, ingressaram no curso 231 alunos e evadiram 144 (por diferentes motivos).

Estes números têm sido um fator preocupante para os professores do Instituto de Matemática, Estatística e Física (IMEF) que lecionam as disciplinas dos semestres iniciais. Além disso, estes dados geram ansiedade e frustração, tanto nos acadêmicos quanto nos docentes. Acreditamos que uma das causas para o alto índice de evasão é que o curso de Bacharelado em Matemática Aplicada para muitos é, hoje, um curso de transição: os acadêmicos ingressam buscando uma preparação para os cursos de Engenharia (por exemplo, Engenharia de Computação, Mecânica, Civil, etc.). Outro motivo aparente é a falta de conhecimentos elementares de matemática por parte dos alunos. Esta falha na formação básica dificulta o acompanhamento das disciplinas iniciais do curso e se reflete nas demais, comprometendo a formação do aluno como um todo. A experiência tem nos mostrado que o estudante tem muita dificuldade de superar este problema sozinho.

Segundo Franchi (2003), pesquisas realizadas para determinação do perfil de alunos ingressantes nos cursos da área de Exatas e Engenharia têm demonstrado que muitos estudantes apresentam falhas de aprendizagem em conteúdos de ensino fundamental e médio dificultando o acompanhamento das disciplinas que compõem os currículos básicos dos primeiros anos de sua formação. Tais dificuldades são também evidentes em sistemas de avaliação de ensino existentes no país, como o Sistema Nacional de Avaliação da Educação Básica (SAEB), o Programa Internacional de Avaliação de Alunos (PISA) e o Exame Nacional do Ensino Médio (ENEM) (FERREIRA; BRUMATTI, 2009).

Um estudo realizado pelo movimento Todos pela Educação (2013) mostrou que apenas 10\% dos jovens brasileiros que concluem o ensino médio sabem matemática. Para grande parte, a disciplina nunca foi a matéria preferida. $O$ levantamento revela ainda que o desempenho dos estudantes piorou, já que no ano de 2009 o percentual era de $11 \%$. Em pesquisa publicada na revista Veja, Nathalia Goulart (2010) afirma que o ensino público brasileiro está de recuperação, pois dados do SAEB indicam que $70 \%$ dos alunos das séries avaliadas (quinto e nono anos do ensino fundamental e terceiro do ensino médio) não atingiram níveis de aprendizado considerados adequados em língua portuguesa e matemática. $\mathrm{O}$ número mais alarmante está no terceiro ano do ensino médio: apenas $9,8 \%$ dos alunos dominam conhecimentos que deveriam saber em matemática.

Com relação ao ensino superior, o quadro acima descrito não é diferente. Segundo o site da BBC Brasil, na reportagem de Costas (2013), 'Geração do diploma' lota faculdades, mas decepciona empresários, o Brasil, de maneira geral, tem um grande desafio pela frente que é melhorar a qualidade do ensino superior, pois

[...] o índice de analfabetismo funcional entre universitários brasileiros chega a $38 \%$, segundo o Instituto Paulo Montenegro (IPM), vinculado ao Ibope. $\mathrm{Na}$ prática, isso significa que quatro em cada dez universitários no país até sabem ler textos simples, mas são incapazes de interpretar e associar informações. Também não conseguem analisar tabelas, mapas e gráficos ou mesmo fazer contas um pouco mais complexas.

Baseado na situação em que se encontram os ensinos médio e superior, é fato que existe um descompasso entre o que se espera dos acadêmicos e o seu desempenho real. Não é uma tarefa simples e muito menos objetiva operar a evolução de um quadro preocupante para uma 
melhora concreta na qualidade do que se ensina e no conhecimento que os acadêmicos se apropriam na prática. Podemos, de maneira subjetiva, traçar um panorama através de pontos que julgamos essenciais para que uma mudança possa ser construída.

A fim de identificar os primeiros passos para dar início a esta construção, inicialmente, decidimos descrever o cenário em que se encontram os sujeitos de nossa pesquisa. No primeiro semestre os alunos cursam as disciplinas obrigatórias de Introdução ao Cálculo (6 créditos), Introdução ao Uso de Recursos Computacionais (3 créditos), Fundamentos de Matemática (4 créditos) e Geometria Analítica I (4 créditos). Independentemente do desempenho do acadêmico no primeiro semestre, o mesmo está apto a se matricular no segundo semestre, isto é, nas disciplinas: Cálculo I Geometria Analítica II, Algoritmos e Programação de Computadores I, Técnicas de Contagem e Análise Exploratória de Dados.

O objetivo geral do primeiro semestre é fornecer aos acadêmicos do curso subsídios que os capacitem a resolver problemas envolvendo conceitos elementares de matemática, bem como aprimorar as habilidades cognitivas: memória, manipulação algébrica, organização discursiva e raciocínio lógico. Além disso, apresentar ao aluno softwares de computação simbólica e editores de textos matemáticos e preparar o estudante para a disciplina de Cálculo I.

Com a finalidade de alcançar o propósito deste artigo, analisamos no sistema acadêmico o aproveitamento desses alunos nas disciplinas do primeiro semestre. Os detalhes dos dados obtidos estão ilustrados na Figura 1. Ela apresenta um comparativo entre o desempenho dos estudantes nas disciplinas obrigatórias do primeiro semestre do ano de 2013. Observa-se que o número de aprovados não ultrapassa 30\% em nenhuma das disciplinas. Na prática, em uma turma de 40 alunos calouros, no máximo 12 foram aprovados. A evasão é significativa e, em duas situações, representa um percentual maior do que a reprovação por nota sendo que, na disciplina de Geometria Analítica I, os percentuais praticamente se igualam.

$\mathrm{Na}$ tentativa de elucidar as razões para os dados apresentados, pesquisamos o aproveitamento dos alunos do curso em questão, nas mesmas disciplinas, para o primeiro semestre do ano de 2009. Em particular, esta foi a primeira turma que ingressou via vestibular de verão. Na Figura 2, observamos que em relação ao ano de 2013 o total de aprovados foi consideravelmente maior. Além disso, as reprovações por nota e frequência foram menores.

Levando em conta o fato de que desde o início do curso, as disciplinas analisadas são ministradas pelo mesmo grupo de professores, tendo como ponto de partida o perfil dos alunos traçado por esta pesquisa, buscamos alternativas tanto para esclarecer os motivos quanto para melhorar tais indicadores.

Acreditamos que o aluno ingressante se mostra imaturo diante da realidade acadêmica. A cada ano os alunos chegam aos cursos superiores mais jovens e em dúvida quanto ao curso que escolheram. Além disso, no ensino médio o ritmo de estudo é bem diferente do que aquele cobrado pela universidade, onde o aluno deve ter o hábito de estudo contínuo e aprofundado e, assim, deve dedicar mais tempo ao estudo dos conteúdos das disciplinas, sem esperar somente pelo professor. Segundo Gazire (2006), os alunos estão acostumados a um ritmo tradicional de ensino onde o professor é o detentor do saber e tem a obrigação de passá-lo pronto e acabado.

De acordo com Soares e Sauer (2004), para ensinar não é suficiente expor e informar, mas principalmente, incentivar o aluno a pensar, fazer conjecturas, ler e interpretar informações e, com base nelas, deduzir formas de resolver problemas, interagindo com os colegas, refletindo sobre as ações desenvolvidas e tomando decisões. Dessa forma, acreditamos que há a necessidade de uma mudança de postura do aluno e dos professores. Concordamos com Barnes (1995), que afirma que o "super aluno" é apenas um mito, esperamos, entretanto, que o aluno seja capaz de controlar a própria aprendizagem, e não deixe tudo para a "última hora". 


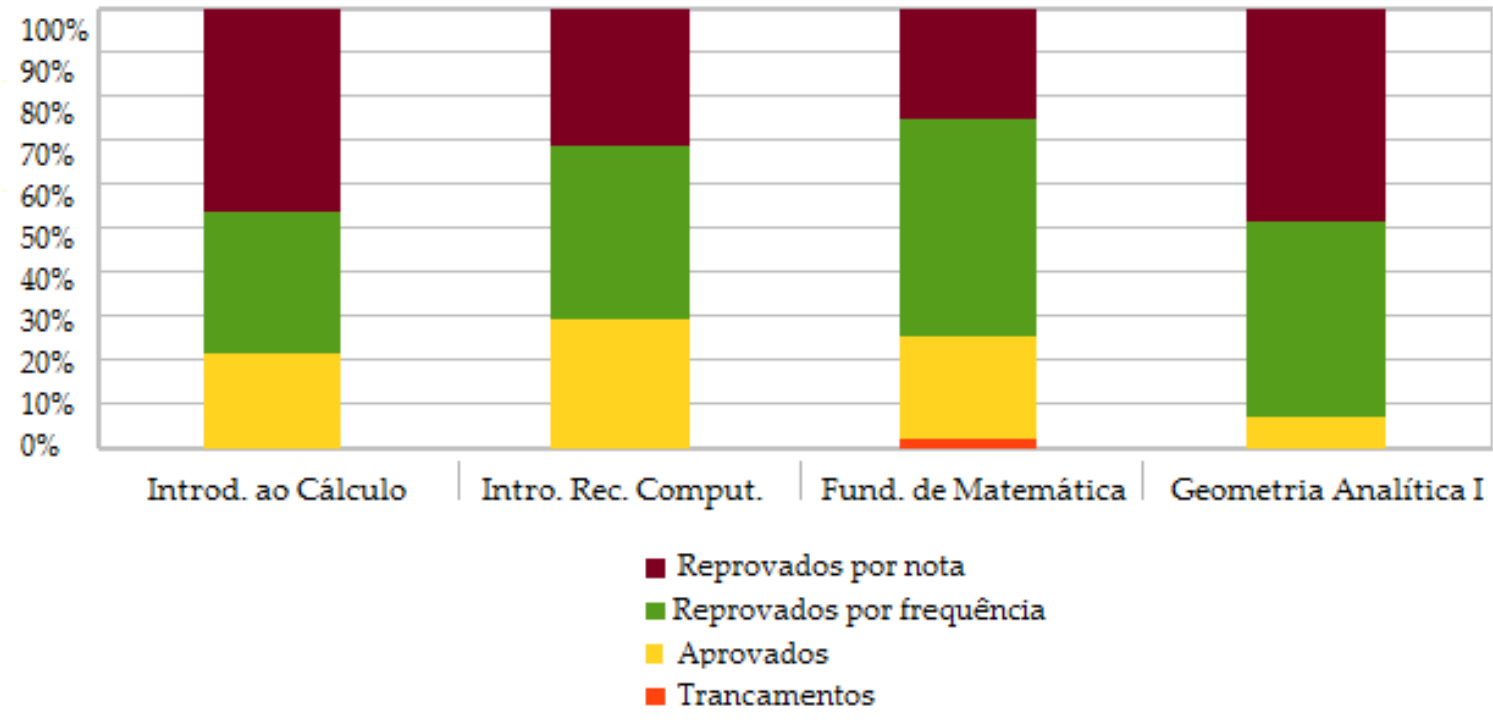

Figura 1. Aproveitamento dos alunos nas disciplinas obrigatórias do primeiro semestre do ano de 2013.

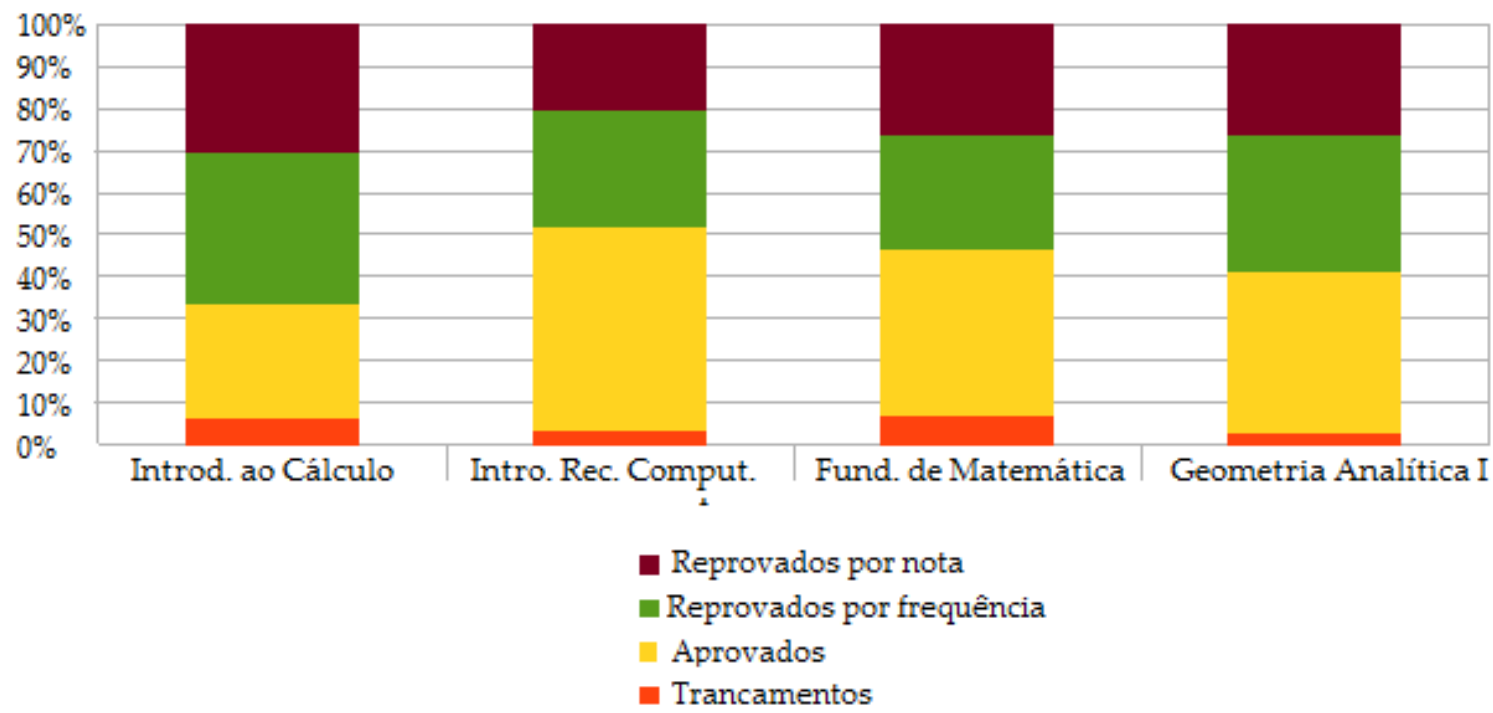

Figura 2. Aproveitamento dos alunos nas disciplinas obrigatórias do primeiro semestre do ano de 2009.

De acordo com Soares e Sauer (2004), em geral, os alunos apenas manipulam símbolos e resolvem exercícios mecanicamente. Parecem realmente não pensar no que fazem. Muitos conseguem resolver os problemas propostos por similaridade, sem entender os conceitos envolvidos. Muitas vezes quando questionados sobre a forma de solução, respondem: "fiz, mas não sei se está certo", "fiquei com dúvidas, mas fiz todos os problemas", "preciso do gabarito". Tais expressões revelam que nossos estudantes iniciam o curso sem terem desenvolvido as estruturas cognitivas relacionadas à interpretação da linguagem matemática, à compreensão de conceitos que são pré-requisitos para o desenvolvimento de novos. Revelam também dificuldades em habilidades como tomada de decisão, reflexão, exploração e dedução. Por outro lado, pode ser inferido que os alunos guardam a técnica e não os conceitos. Isso é bem visível, quando eles verbalizam que precisam de exercícios feitos para ver como é a solução. 
Especificamente no que se refere ao alto percentual de evasão, e com o desafio de lidar com as nossas próprias expectativas, acreditamos que através do perfil do aluno perceberemos que uma das causas deste fato é o despreparo do acadêmico, que não está suficientemente qualificado, e finalmente, acaba abandonando o curso. Oliveira Júnior (2013) acredita que o número alto de alunos evadidos esteja relacionado ao despreparo dos alunos que são aprovados para o curso de Matemática, sem realmente terem os pré-requisitos básicos para cursá-lo. Além disso, o fracasso acadêmico desmotiva a permanência em um curso cujo mercado de trabalho ainda desconhece as potencialidades. Hoje em dia, em uma cultura que favorece o retorno imediato, é uma tarefa difícil convencer os jovens sobre os atrativos de uma atividade que tem, algumas vezes, um retorno lento em termos de gratificação financeira, intelectual e emocional.

Alguns autores, por exemplo, Catani, Oliveira e Dourado (2001) consideravam que uma das causas da evasão nos cursos de graduação era devido a pouca flexibilidade dos currículos escolares diante das mudanças que ocorriam no mundo do trabalho e por este motivo, faziam com que os cursos ficassem desatualizados e desinteressantes para os estudantes. Na FURG, por exemplo, já houve uma reformulação curricular neste sentido em 2011, atualmente o núcleo docente estruturante (NDE) do curso está elaborando uma proposta para a criação de três ênfases de formação, uma tentativa de direcionar os estudos e motivar a permanência dos discentes. Além disso, há projetos de iniciação científica, ensino e extensão com bolsas de estudos que pretendem motivar os alunos para concluir o curso e se lançarem no mercado de trabalho. Outra iniciativa para direcionar os alunos a trabalhar com problemas reais e que venham a ser resolvidos por teoremas e proposições é a criação da Empresa Júnior de Matemática Aplicada. Mas acreditamos que um maior reconhecimento social, assim como melhores salários aos profissionais formados são essenciais para atrair melhores matemáticos para a graduação.

\section{Métodos e materiais}

Este artigo, com relação à abordagem do problema, ampara-se no paradigma qualiquantitativo, pois relaciona o ambiente acadêmico, o sujeito e a pesquisa. Quanto aos fins, trata-se de um objeto explicativo, pois visa esclarecer quais fatores, de alguma forma, contribuem para o insucesso dos ingressantes do curso de Matemática Aplicada do ano de 2013.

A nossa pesquisa foi desenvolvida através das seguintes etapas metodológicas:

- Levantamento do desempenho dos acadêmicos nas disciplinas do primeiro semestre e do percentual de evasão do curso desde 2008;

- Identificação das disciplinas em que ocorreu o maior percentual de retenção;

- Elaboração e aplicação de questionário para análise do perfil dos acadêmicos no primeiro semestre de 2013;

- Análise dos resultados com identificação dos principais fatores que levam à repetência e evasão;

- Busca de soluções alternativas para amenizar a reprovação e a evasão.

Após a descrição do cenário acadêmico em que se encontram os discentes e a identificação das disciplinas em que ocorreu o maior percentual de retenção, elaboramos um questionário a ser respondido pelos alunos do primeiro semestre do curso.

\section{Apresentação e análise dos dados}

Obtivemos os dados para a realização deste trabalho através da aplicação de um questionário composto por treze (13) questões, oito (8) objetivas e cinco (5) discursivas, essencialmente sobre a formação de matemática básica dos acadêmicos e suas principais dificuldades na formação no ensino superior. Estavam presentes no momento em que o instrumento foi aplicado vinte e oito (28) alunos do primeiro semestre do curso de Matemática Aplicada - Bacharelado da FURG em 2013. Estes alunos ingressaram através do Sistema de Seleção Unificada SISU/MEC, de acordo com o regulamento vigente da universidade, distribuídos em três chamamentos. 
A pesquisa foi realizada nas dependências da FURG no dia 31 de julho de 2013, em sala de aula e na presença dos professores. Antes de entregar o questionário explicamos a natureza da pesquisa e os alunos aderiram voluntariamente ao processo de investigação. Não foram produzidos vídeos, nem fotografias.

O questionário foi elaborado de modo a conter perguntas simples e de fácil entendimento; relativamente curto, para não se tornar cansativo e fazer com que o aluno se sentisse desestimulado a responder até o fim. De um modo geral, as questões buscam caracterizar as particularidades da formação matemática dos alunos, ora por meio de questões objetivas, ora por meio de questões discursivas.

A primeira parte do questionário visa caracterizar os alunos em relação aos seus dados pessoais, tais como idade e sexo. Já num segundo momento, o instrumento busca informações mais precisas sobre o tipo e a qualidade da formação escolar e o interesse demonstrado na procura da monitoria e dos professores a fim de esclarecer suas dúvidas na disciplina. A parte final do questionário trata de, na opinião dos acadêmicos, listar as principais dificuldades de sua formação no ensino superior.

A seguir, apresentamos cada questão proposta, seguida da descrição das respostas obtidas e uma breve discussão dos resultados.

\subsection{Dados de identificação}

Primeiramente, os dados de identificação solicitados foram: nome, data e idade. Caso o aluno desejasse, poderia não se identificar.

Dados Pessoais
Nome:
Data:

Todos os 28 alunos responderam prontamente aos dados acima. No que se refere ao perfil sócio demográfico dos alunos do curso de Matemática Aplicada - Bacharelado da FURG, ficam evidentes alguns aspectos como a diferença entre o número de alunos do sexo masculino, 39,3\% e o número de alunos do sexo feminino, $60,7 \%$.
A faixa etária dos discentes é distribuída da seguinte forma: 17 alunos com menos de 20 anos, 8 alunos entre 21 e 30 anos e 3 alunos acima de 30 anos. Desse modo, concluímos que os sujeitos de nossa investigação são jovens e a maioria do sexo feminino. Outras pesquisas realizadas em diferentes faculdades no país (por exemplo, na FACOS, Osório - RS e na AJES, Juruena - MT) também concluíram que a maioria dos ingressantes nos cursos de Matemática tem menos de 25 anos e são do sexo feminino (GOLDANI; ALVES et. al., 2013).

Portanto, estamos diante da "geração internet", dos nascidos após 1990. Segundo Wolynec (2006), esta geração possui habilidades cognitivas diferenciadas, como a capacidade de aprender com recursos audiovisuais e a facilidade em trabalhar com o computador.

\subsection{Escolaridade}

A segunda parte do questionário abordava o tipo de escolaridade dos discentes.

Dos alunos que responderam ao questionário, 23 terminaram o ensino médio há

1. Teve algum intervalo de tempo entre o ensino médio e o ensino superior?

( ) Sim ( ) Não - Qual foi este tempo?

2. Que tipo de ensino médio você frequentou?
( ) Normal
( ) Profissionalizante/Técnico
( ) EJA ( ) Outros

3. Seu ensino médio foi em que tipo de Escola?

( ) Particular ( ) Pública ( ) Outras.

no máximo 3 anos. Além disso, dentre os 28 alunos, 21 cursaram o ensino médio em escola pública e 20 terminaram o ensino médio regular. Quanto aos demais, 3 cursaram o ensino profissionalizante, 2, Educação de Jovens e Adultos (EJA) e 2, magistério. Decorrem dos dados supracitados que mais de $80 \%$ dos alunos concluiu recentemente o ensino médio. A grande maioria cursou o ensino regular em escola pública. Goldani (2012) e Oliveira Júnior (2013) em suas pesquisas também concluíram que a maioria dos alunos cursou o ensino médio regular. Oliveira Júnior (2013) afirma ainda que 
ao se conhecer tal aluno é possível analisar se o ensino fundamental e médio público tem uma qualidade de formação que se assemelhe ao ensino privado no que tange à qualidade, mas isso pode somente ser comprovado através de uma comparação entre os desempenhos dos que só estudaram na rede pública com os que vieram unicamente do ensino privado.

\subsection{Dificuldades na aprendizagem em Matemática}

A terceira parte do questionário investigava as principais dificuldades em matemática durante os ensinos médio e superior.

4. Você teve dificuldades em matemática no ensino médio? ( ) Sim ( ) Não

5. A matemática do ensino médio capacitou-lhe para a matemática do ensino superior? ( ) Sim ( ) Não

6. Teve dificuldade em alguma disciplina no ensino superior? ( ) Sim ( ) Não

Em caso afirmativo, que atitude(s) você tomou para superar estas dificuldades?

( ) Monitoria ( ) Aula Particular

( ) Estudo em Grupo ( ) Outros:

Apesar de, do total de alunos que responderam o questionário, 25 admitirem ter dificuldades em alguma disciplina do ensino superior, 24 disseram não ter tido dificuldades em matemática no ensino médio. 17 alunos afirmaram, ainda, que a matemática do ensino médio não os capacitou para a matemática do ensino superior.

Em uma pesquisa realizada no Unilasalle (Centro Universitário La Salle) em Canoas - RS, no ano de 2007, Filber (2007) obteve o mesmo resultado, ou seja, a maioria dos alunos afirmava não ter tido dificuldades no ensino médio, mas acreditava que seus conhecimentos não os capacitavam para o ensino superior.

Estes fatos provocam e motivam uma reflexão sobre as estratégias de aprendizagem que estão sendo adotadas. Duas questões podem ser discutidas sobre a relação entre o sucesso acadêmico no ensino médio e o início difícil do ensino superior: a primeira refere-se à diferença entre o modo como os alunos são avaliados em cada etapa e a segunda, supondo que o aluno foi constantemente bem avaliado, sobre a existência de uma lacuna entre os conceitos que ele não sabe e não consegue aplicar.

Com o objetivo de fazer com que os alunos refletissem sobre como estão estudando e qual a melhor forma para cada um ampliar o aprendizado, isto é, fazê-los "aprender a aprender" (VALENTE, SALEMA, MORAIS \& CRUZ, 1989), os mesmos foram questionados sobre quais atitudes tomaram para sanar suas atuais dificuldades. A maioria citou o estudo em grupo e individual. Apenas um aluno citou que procura a monitoria. Filber (2007) obteve resultados semelhantes. Tal atitude mostra a imaturidade e despreparo para estudar, reforçando a necessidade de esclarecer uma perspectiva sobre as diferenças de cada indivíduo no rendimento escolar (RIBEIRO, 2003).

\subsection{Expectativas em relação à Matemática no ensino superior}

Para aprofundar a discussão das dificuldades na aprendizagem em matemática, os alunos foram questionados quanto as suas expectativas em relação aos conteúdos matemáticos estudados no ensino superior, incluindo questões discursivas para entender melhor a visão do acadêmico.

7. A matemática exigida no ensino superior está dentro do que você apreendeu no ensino médio? ( ) Sim ( ) Não

8. Você imaginava que teria dificuldades em Matemática ao ingressar no ensino superior? ( ) Sim ( ) Não

9. Qual sua opinião em relação à matemática exigida no ensino superior?

10. O nível de matemática no ensino superior está dentro do esperado para o curso que você escolheu? Justifique.

Sobre os conteúdos do ensino superior, a maioria acredita que estes são abordados de forma mais aprofundada do que no ensino médio, necessitando de mais estudo. Além disso, pensam que o nível de exigência do curso está dentro do que era esperado. Em suas justificativas, muitos alunos citam que não esperavam um curso tão difícil, mas 
reconhecem a qualidade do mesmo. Veja algumas respostas para a questão 9:

A matemática do ensino superior exige mais dedicação, mais foco e mais objetividade. (D.H.M.)

Na minha opinião, o ensino médio foi muito fraco porque muitas coisas deveria ter aprendido no médio para ter um pouco de noção no superior. (L.M.C.)

O primeiro comentário sinaliza que a necessidade de comprometimento com os estudos é deixada de lado por muitos. Já o segundo, está de acordo com a questão apresentada anteriormente: o que faltou ter aprendido? Será que não faltou ter aprendido a estudar?

Apesar de 9 alunos admitirem que a matemática estudada no ensino superior está de acordo com a matemática do ensino médio (reconhecem que estão apenas no início), 13 dizem que imaginavam que teriam dificuldades no ensino superior. Veja o comentário de um aluno para a questão 10:

Sim, mas mesmo assim encontrei dificuldades por não ter uma base adequada ao nível superior. (L.M.A.)

A "base adequada" citada pelo aluno e que aparentemente refere-se ao aprendizado dos conteúdos pode ser ampliada para um sentido de amadurecimento para pesquisar e buscar novos conhecimentos, como discutimos nas respostas da questão 11. Segundo Brolezzi (2007), o que era exigido do aluno na escola básica era mais uma habilidade operacional da Matemática, e menos uma abordagem conceitual. Além disso, a própria natureza da Matemática muda na passagem para o ensino superior.

\subsection{Revisão de conteúdos anteriores}

Para identificar a postura do aluno diante de uma dúvida, foi questionada qual a atitude tomada quando surge um assunto que é prérequisito para aquele que está sendo estudado.
Como alternativa para sanar as dificuldades apresentadas, 18 alunos citam livros didáticos como fonte de pesquisa, causando certa surpresa, pois acreditávamos que a internet seria a campeã de respostas.

11. Caso você tenha dúvidas, sobre conteúdos anteriores que você não se recorda, você pede ao professor para the relembrar este conteúdo, pesquisa em livro ou deixa assim, não se interessa em relembrar?

12. Você gostaria que tivesse um tempo antes ou depois da aula para perguntar sobre conteúdos que já se esqueceu?

Veja uma das respostas para a questão 11:

Tento relembrar, através de pesquisa e ajuda de colegas que saibam. Muitas vezes tenho receio de perguntar, pois para o professor pode parecer tolo. (C.A.T.)

Quando questionados sobre a necessidade de um tempo durante as aulas para esclarecimento de dúvidas sobre o que chamamos de conteúdos pré-requisito, 19 alunos afirmaram que gostariam. No entanto, pela nossa experiência, quando são realizadas aulas de exercícios, muitos alunos não comparecem ou apenas assinam a lista de chamada e saem.

\subsection{Conteúdos a serem aprofundados}

Finalmente, com relação aos conteúdos do ensino médio que deveriam ser aprofundados, foram citados com maior frequência a geometria analítica, a trigonometria e os logaritmos (nesta ordem), como mostra a resposta a seguir:

Bom, no meu caso, houve vários, pois no primeiro e segundo ano eu fiquei sem professor. Ex: geometria analítica, entre outras que não lembro. Mas fiz cursinho e isso me ajudou a ter uma base no que estou aprendendo agora. (F.J.) 
Em sua pesquisa, Curi (2011) observou que conteúdos matemáticos importantes, como Trigonometria, Função Logarítmica, Probabilidade e Combinatória não tinham sido estudados pelo grupo de alunos ingressantes em um curso de Matemática.

Na resposta do aluno, aparece um agravante que ainda não havíamos considerado: a falta de professores de matemática na educação básica. Realidade que justifica o fato de muitos alunos sequer terem sido apresentados ao conteúdo, impedindo uma associação com o cotidiano e, consequentemente, a aprendizagem. Quando o professor assume a turma, muitas vezes, não é mais possível cumprir com êxito o plano de ensino. Hilário Alencar, presidente da Sociedade Brasileira de Matemática (SBM), em entrevista para o Jornal do Professor em 2009 afirma que a falta de professores de matemática no Brasil

[...] se deve fundamentalmente aos degradantes salários pagos aos professores. Os formados para este nível de ensino preferem ir fazer outra coisa que lhes pague melhor. No entanto, para o nível universitário a falta se deve realmente a limitação no número de formados. Vale lembrar que a profissão de matemático, bem como a de professor de matemática, não possui o charme e o apelo social de outras profissões como: médico, advogado, economista, jornalista, engenheiro, etc. Por outro lado, um bom matemático sempre estará empregado.

Observamos que as disciplinas de Fundamentos de Matemática, Introdução ao Cálculo e Geometria Analítica I têm as maiores taxas de reprovação. A maioria dos nossos discentes acredita que sua formação no ensino fundamental e médio não é suficiente para acompanhar os conceitos do ensino superior. Apesar disso, não buscam alternativas como a monitoria e o horário de atendimento com os professores. Como podemos incentivar a participação dos alunos nesses serviços oferecidos pela universidade? Precisamos iniciar uma cultura de mudanças de hábitos dos estudantes, talvez possamos criar situações em que procurem os monitores e o atendimento dos professores. Uma sugestão seria $o$ desenvolvimento de oficinas e projetos de ensino específicos para a discussão de conteúdos matemáticos importantes e suas aplicações.

\section{Conclusão}

Segundo pesquisas, os cursos de engenharias (FRANCHI, 2003) e ciências exatas (BASNIAK, 2012) têm dificuldades em admitir alunos com o perfil desejado e esforços estão sendo feitos no sentido de realizar mudanças (BITTAR et. al, 2012). Investigar o perfil dos alunos e suas principais dificuldades é um ponto de partida essencial para auxiliá-los a permanecer nos cursos e obter sucesso acadêmico e profissional.

A lei no 12.089 de 11 de novembro de 2009 proibiu uma mesma pessoa de ocupar, na condição de estudante, duas vagas, no mesmo curso ou em cursos diferentes em uma ou mais instituições públicas de ensino superior em todo o território nacional, fazendo com que muitos alunos dos cursos de engenharia e correlatos abandonassem o curso de Matemática. Acreditamos que não por falta de aptidão, mas em busca de uma formação em cursos já consagrados e conhecidos, cujas compensações e atribuições são mais atraentes.

Este trabalho tem um caráter explicativo, no sentido de tornar-se uma base de dados a respeito dos alunos iniciantes do Curso de Matemática Aplicada Bacharelado - FURG. Estes dados constituem uma fonte de análise para auxiliar no encaminhamento das alterações e adaptações que possam vir a ser executadas, sempre com o objetivo da melhoria do ensino superior de Matemática em todo Brasil. Acreditamos que as dificuldades apontadas são recorrentes nas demais regiões e há necessidade de compartilharmos nossa realidade para que experiências vitoriosas possam ser discutidas e aproveitadas por todos.

Em geral, o aluno ingressante no curso de Matemática Aplicada da FURG em 2013 foi do sexo feminino, com idade inferior a 20 anos, terminou o ensino médio regular em escola pública, há no máximo 3 anos. Este aluno acredita que a matemática do ensino médio não 
o capacitou para a graduação, embora acredite que o nível de exigência do ensino superior está dentro do esperado. Ainda, para solucionar suas dúvidas, o estudante não costuma procurar monitores e os professores ou participar de aulas de exercícios.

As disciplinas do primeiro semestre, projetadas para preparar os alunos para um melhor aproveitamento do curso, são muito parecidas com as de cursos de Matemática em geral. Quanto ao papel delas, segundo o coordenador atual da Matemática Aplicada da FURG (2014),

Aqueles alunos que se destacam e até poderiam prosseguir no curso, não parecem precisar delas. Poderiam inclusive - para melhor proveito deles e do curso - ser dispensados dessa "revisão" que fazemos. (M.R.R.)

Mas para a maioria dos professores, a justificativa da sua existência é apontar caminhos com a intenção de que os alunos aprendam a estudar e tomem consciência de seu papel e responsabilidades (SEVERINO, 2002). Não nos isentamos de nosso compromisso como educadores e mestres em apontar o caminho, quantas vezes forem necessárias, para que o aluno se torne crítico e capaz de organizar seus estudos.

Por outro lado, ao final do questionário, estabelecemos ao nosso trabalho uma condição reflexiva, pois a partir do conhecimento do perfil dos estudantes ingressantes na nossa universidade poderemos planejar ações de assistência estudantil que contemplem as necessidades dos estudantes. Além disso, isso proporcionará subsídios para uma melhor interação entre professor-aluno e para o processo de ensino-aprendizagem, aumentando a satisfação do aluno em relação ao curso e, consequentemente, reduzindo a taxa de evasão. Uma ação docente bem planejada é capaz de evitar a evasão, pois segundo Barroso (2004):

Este trabalho exige a utilização de métodos que privilegiem o trabalho ativo do estudante em sala de aula, o desenvolvimento de técnicas que façam com que o aluno desenvolva trabalhos cooperativos com os seus colegas e com os professores da instituição, o desenvolvimento de materiais didáticos apropriados que permitam a superação do fosso entre o conteúdo e a forma de trabalho dos alunos no ensino médio e na universidade.

Na FURG, atualmente o núcleo docente estruturante do curso (NDE) do curso de Matemática Aplicada está elaborando uma proposta de criação de ênfases de formação. Além disso, há projetos de iniciação científica, ensino e extensão com bolsas de estudos e a Empresa Júnior de Matemática Aplicada. Essas iniciativas encaminham os estudantes ao mercado de trabalho e motivam a permanência dos estudantes no curso.

Com o objetivo de verificar se os conteúdos matemáticos citados pelos alunos ao longo desta pesquisa são, na prática, os mais difíceis, futuramente pretendemos aplicar um questionário de conhecimentos para investigar os pontos críticos de cada conteúdo.

\section{Referências}

ALENCAR, H. Matemática não é difícil. [26 de agosto, 2009]. Entrevista concedida ao Jornal do Professor. Disponível na Internet. http://portaldoprofessor.mec.gov.br/jornal.ht ml Acessado em 01 de novembro de 2013.

ALVES, M.; ZANIOLO, L.; SILVA, F.; TANEDA, $M$. Perfil do acadêmico ingressante no curso de matemática de uma faculdade do noroeste do estado de Mato Grosso, Brasil. Disponível na Internet. http://www.ajes.edu.br/arquivos/20130917150 221.pdf Acessado em 31 de outubro de 2013.

BARNES, R. Seja um ótimo aluno - guia prático para um estudo universitário eficiente. 1. ed. Campinas, Papirus, 1995. 228 p.

BARROSO, M. F.; FALCÃO, E. B. M. Evasão universitária: O caso do Instituto de Física da UFRJ. IX Encontro Nacional de Pesquisa em Ensino de Física. Rio de Janeiro, 2004. Disponível na Internet. http://www.sbf1.sbfisica.org.br/eventos/epef/i 
x/atas/comunicacoes/co12-2.pdf Acessado em 30 de outubro de 2013.

BASNIAK, M. I. Avaliação em Matemática: algumas reflexões a partir de um estudo realizado no curso de Licenciatura em Matemática. Em Teia - Revista de Educação Matemática e Tecnológica Ibero-americana, Recife, vol. 3, n. 2, p. 1-16, 2012.

BITTAR, M.; OLIVEIRA, A.; SANTOS, R., BURIGATO, S. A evasão em um curso de Matemática em 30 anos. Em Teia - Revista de Educação Matemática e Tecnológica Iberoamericana, Recife, vol. 3, n.1, 2012. Disponível em: http://www.gente.eti.br/revistas/index.php/e mteia/article/view/60 Acessado em 04 de novembro de 2013.

BRASIL. Lei $\mathrm{n}^{\mathrm{o}}$ 12.089, de 11 de novembro de 2009. Proíbe que uma mesma pessoa ocupe 2 (duas), vagas simultaneamente em instituições públicas de Ensino Superior. Diário Oficial [da República Federativa do Brasil], Brasília, DF.

BROLEZZI, A. C. Pensamento reverso no ensino de matemática. In: IX Encontro Nacional de Educação Matemática, 2007, Belo Horizonte. Anais. CD-ROM.

CATANI, A.; OLIVEIRA, J.; DOURADO, L. Política educacional, mudanças no mundo do trabalho e reforma curricular dos cursos de graduação no Brasil. Educação e Sociedade, Campinas, v. 22, n.75, p. 67-83. Ago/2001.

COSTAS, R. "Geração do diploma" lota faculdades, mas decepciona empresários. São Paulo: BBC Brasil, 09 de outubro, 2013. Disponível na internet: http://www.bbc.co.uk/portuguese/noticias/20 13/10/131004_mercado_trabalho_diplomas_ru .shtml Acessado em 05 de novembro de 2013.

CURI, E.; SANTOS, C.A.B. Algumas reflexões sobre o tratamento de conteúdos do ensino básico em um curso de licenciatura em matemática. Em Teia - Revista de Educação Matemática e Tecnológica Ibero-americana, Recife, v. 2, n. 2, p. 1-19, 2011.

FERREIRA, D., BRUMATTI, R. Dificuldades em matemática em um curso de engenharia elétrica. Horizontes, s.l., v. 27, n.1, p. 51-60. Jan-Jun/ 2009.

FILBER, C. Dificuldades em Matemática ao ingressar no ensino superior. Disponível na Internet.

http://biblioteca.unilasalle.edu.br/docs_online /tcc/graduacao/matematica/2007/cfgoncalves. pdf Acessado em 31 de outubro de 2013.

FRANCHI, R. In: XXXI Congresso Brasileiro de Ensino de Engenharia, 2003, Rio de Janeiro. Enfrentando as falhas na formação básica dos alunos Ingressantes. Anais. CDROM.

UNIVERSIDADE FEDERAL DO RIO GRANDE (FURG). Projeto político pedagógico do curso de Matemática Aplicada. Rio Grande: FURG, 2009.

GAZIRE, E.; LAUDARES, J. B.; ALVES, M. B. In: XXXIV Congresso Brasileiro de Ensino de Engenharia, setembro de 2006, Passo Fundo. Resolução de problemas com equações diferenciais em cursos de engenharia. Anais. p. $1464-1474$.

GOULART, N. Desafios Brasileiros: Por que o aluno brasileiro aprende tão pouco? Revista Veja. Disponível na Internet. http://veja.abril.com.br/noticia/educacao/porque-o-aluno-brasileiro-aprende-tao-pouco Acessado em 23 de outubro de 2013.

GOLDANI, A. Quem são os alunos ingressantes no curso de matemática? Disponível na Internet

http://www.nepso.net/projeto/662/quem_sao_ os_alunos_ingressantes_no_curso_de_matem atica_da_facos Acessado em 31 de outubro de 2013.

OLIVEIRA JUNIOR, A. P. In: XI Encontro Nacional de Educação Matemática, 2013, Curitiba. Os alunos do curso de licenciatura em Matemática da UFTM e suas atitudes em relação à matemática. Anais. p. 1- 15.

MORAIS, M. M.; VALENTE, M. O. Pensar sobre o pensar: Ensino de estratégias metacognitivas para recuperação de alunos com dificuldades na compreensão da leitura na disciplina de língua portuguesa. Revista de Educação, s.l., v.2, n.1, p.35-56, 1991. 
MOVIMENTO TODOS PELA EDUCAÇÃO. Só

$10 \%$ dos alunos que concluem ensino médio sabem matemática, diz ONG. Educação na mídia. Disponível na Internet: http://www.todospelaeducacao.org.br/comun icacao-e-midia/educacao-na-midia/26158/so10-dos-alunos-que-concluem-ensino-mediosabem-matematica-diz-ong/ Acessado em 05 de novembro de 2013.

RIBEIRO, C. Metacognição: um apoio ao processo de aprendizagem. Psicologia: Reflexão e Crítica, Viseu, v.16, n.1, p. 109-116, 2003.

SEVERINO, A. Metodologia do trabalho científico. 22.ed. São Paulo: Cortez, 2002. $235 \mathrm{p}$.

SOARES, E.; SAUER, L. Um novo olhar sobre a aprendizagem de matemática para a engenharia. In: Disciplinas matemáticas em cursos superiores: reflexões, relatos, propostas/ Helena Cury (org.). Porto Alegre, EDIPUCRS, 2004. p. 245-270.

VALENTE, M. O.; SALEMA, M. H.; MORAIS, M. M. \& CRUZ, M. N. A meta-cognição. Revista de Educação, s.1., v. 1 n.3, p. 47-51, 1989.

WOLYNEC, E. O Futuro da Educação Superior. [jun/2006]. Disponível na Internet: http://www.techne.com.br/artigos/Futuro_Ed ucação_Superior.pdf Acessado em 30 de outubro de 2013. 